\title{
Influence of Trainee Characteristics on Acquired Pharmacology Knowledge of Dental Professionals: A Pilot Study
}

\author{
Aftab Ahmed Khan ${ }^{1}$ and Eraj Humayun Mirza² \\ ${ }^{1}$ Researcher, Dental Biomaterials Research Chairs, College of Applied Medical Sciences, King Saud University, \\ Riyadh; SAUDI ARABIA. \\ ${ }^{2}$ Researcher, Department of Biomedical technology, College of Applied Medical Sciences, King Saud University, \\ Riyadh; SAUDI ARABIA.
}

\begin{abstract}
Background: Organizations spend an extensive amount of time and money on training in order to promote employees' learning, development, and job-related competencies. This study examined the influence of trainee characteristics of the dental practitioners attending the continuing medical education (CME) on"dental pharmacology and patient safety" and their effect on acquired knowledge. Methods: The trainee characteristics of the dental practitioners were conceptualized into four dimensions: motivation to learn, reaction to training, expectations from training, and organizational commitment. A questionnaire containing 20 items related to measuring the levels of knowledge acquired from training were included. With SPSS ver. 21, central tendencies and dispersion, Pearson correlation, and simple linear regression were measured $(p<0.05)$. Results: The results of this study found a positive correlation between the independent variables. Through linear regression, a positive correlation between the independent variables and acquired knowledge was discovered. Conclusion: A combination of personality traits is vital for dental professionals to excel in dental training programs.
\end{abstract}

Key words: Acquired Knowledge, Expectation, Organizational Commitment, Motivation, Training.

\section{INTRODUCTION}

Training is defined as any attempt to improve the performance on a job or one related to it. It usually indicates changes in specific knowledge, skills, attitudes, or behaviors. It refers to a planned attempt by an organization to facilitate employees' learning of job related competencies. The aim of training and development programs is to improve the knowledge, skills and behaviors of not only the new employees but also for the current employees and helps them in adjusting to rapidly changing job requirements. ${ }^{1}$ To make training effective, it should involve a learning experience. Training should be designed in such a way that it is in response to identified needs and it should meet the goals of the organization as well as the employees. $^{2}$
World is changing rapidly and in this changing world organizations try to improve their employees' knowledge, skills and abilities through training. Training is an expensive human resource intervention, therefore the organizations want to evaluate their training efforts. Training evaluation apprisesthe employer whether or not the desired training objectives were achieved. Researchers are interested in knowing the variables that foster the level of knowledge, and the factors that explain why certain training programs did not work out. ${ }^{3}$

Three categories of variables have been identified that enhance the level of knowledge. ${ }^{4} \mathrm{~A}$ first characteristic is training design. Next, the work environment such as organizational climate. It is known to effect
Submission Date : 25-02-2016 Revision Date : :04-04-2016 Accepted Date : 17-04-2016

DOI: 10.5530/ijper.50.3.38

Correspondence: Aftab Ahmed Khan,

M.Sc., M.Bioeth, B.D.S Researcher, College of Applied Medical Sciences, King Saud University, Riyadh, 11433, Kingdom of Saudi Arabia. Tel.: +966 59 1125997;

E-mail: aakjk@hotmail.com

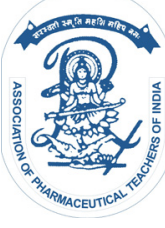

www.ijper.org 
outcomes of training. ${ }^{5}$ Finally, the factors that influence knowledge acquisition are trainee characteristics such as motivation to be trained. ${ }^{6}$

Two decades ago Cannon-Bowers had developed a model of different variables that impact training and affect its outcomes. ${ }^{7,8}$ In this model they have identified various input variables that include training design, trainee characteristics and organization characteristics and their impact on knowledge acquisition.Only a few empirical studies have tested the Cannon-Bowers model. Of these, the most important has been a large-scale study of US navy recruits. In this study, it was found that individual characteristics (e.g. training expectations) were positively related to motivation to learn. ${ }^{9,10}$ Individual characteristics were strongly positively related to indicators of training performance, and motivation to learn and expectation fulfillment were positively related to subsequent job performance. ${ }^{11,12}$ Considering the importance of the trainee characteristics on the acquired knowledge or clinical performance of the dental practitioner, a quantitative research was designed.

This study aims to ascertain whether possessing the four trainee characteristics, i.e., motivation to learn, reaction to training, expectations from training, and organizational commitment could facilitate acquired knowledge from training. Based on discussed literature survey, we hypothesized that there is a relationship between trainees' characteristics (motivation to learn, reaction to training, expectations from training, and organizational commitment) and level of knowledge attained from training.

\section{METHODOLOGY}

\section{Participants}

This cross sectionalanalytical study was conducted in a dental institute of Karachi, Pakistan. The study protocol was approved by the institutional review board of College of Applied Medical Sciences, King Saud University (IRB No. 14-31). Informed consent was waived by the IRB.Prior permission was obtained from the head of the institute and was assured of keeping the name of the institute confidential. The participants of this study were the dental practitioners who had enrolled in a week-long continuing medical education (CME) on "dental pharmacology and patient safety." At the end of a course, a total of 96 questionnaires were distributed among the trainees. Out of 84 returned questionnaires, 29 were rejected because of partially filled-in. There were 55 valid questionnaires.

\section{Measuring instrument}

A questionnaire containing 26 questions was designed in English and administered to the trainees. Six items were related to personal data, the rest 20 items were related to measuring the effect of trainee characteristics on the levels of knowledge acquired from training. Out of these 26 questions, 23 were filled by the trainees and the last 3 questions were filled by their trainer.

\section{Dependent variable}

Acquired knowledge of the trainees was marked on a Likert scale ranging from 1 (highly negative) to 5 (highly positive), with high scores indicative of greater acquired knowledge in training. Three items in the questionnaire were planned to procure the course supervisor's assessment.

\section{Independent variables}

Expectations from training were appraised using seven items from the questionnaire, with questions related to "usefulness of the training in future endeavors" and "the extent to which expectations were accomplished". A high score reflected a high degree of expectations on a Likert scale.

Similarly, motivation to learnwas measured using three items with questions such as "potency of motivation on acquired knowledge"; reaction to training was gauged using two items with questions such as "extent to which training satisfaction was achieved"; and finally an organizational commitment was evaluated using two items with questions such as "role of emotional attachment with the organization in acquired knowledge".

\section{Statistical analysis}

The collected data were analyzed with the Statistical Program for Social Sciences (SPSS, Chicago, IL, USA) version 21.0. The data were mostly measured through the measure of central tendencies and measure of dispersion. Regression analysis was used to find the relationship between knowledge acquisition and other independent variables (Motivation to Learn, Trainees Reactions, Expectation fulfillment and Commitment). Pearson correlation was used to measure the correlation between items on one to one basis. The $p$ value was set at 0.05 .

\section{RESULTS}

Table 1 shows the correlationmatrix of the independent variables of this study. A positive correlation found to exist among the variables of this study. The variable "motivation to learn" showed a moderate(positive) relationship i.e., $\mathrm{r}=0.61$ to "expectations from training". 


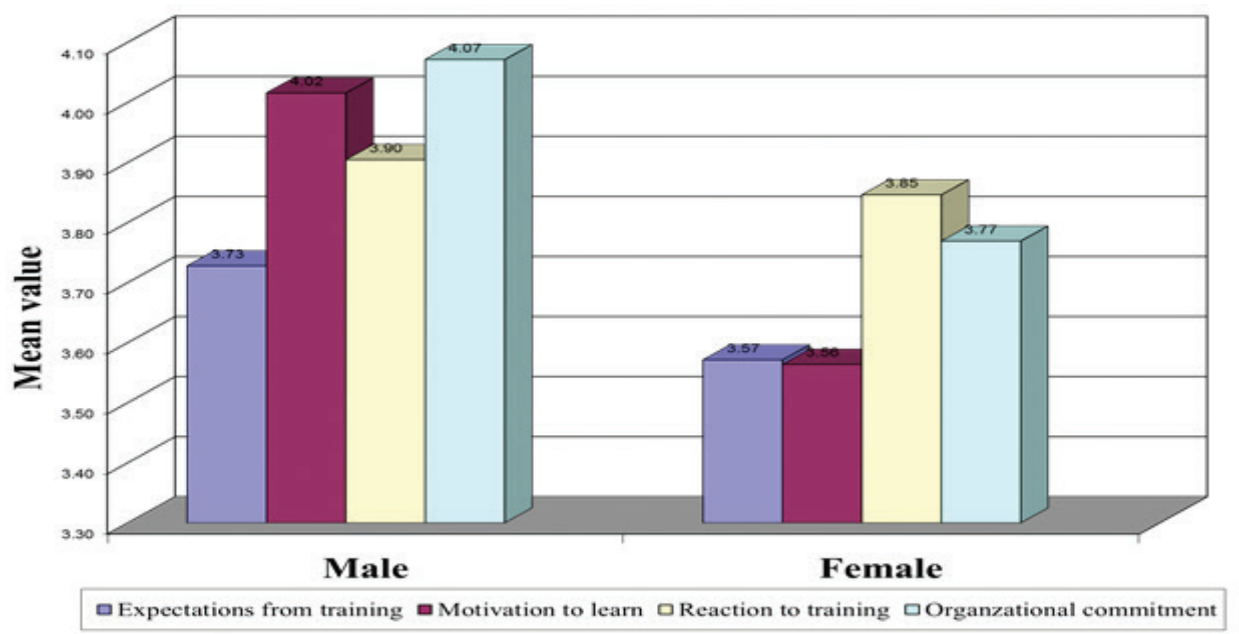

Figure 1: Participants' opinion on trainee characteristics affecting knowledge acquired from training. The y-axis showing he mean values obtained on Likert scale.

\section{Table1: Describes the Pearson correlation matrix of trainees' characteristics}

\begin{tabular}{|c|c|c|c|c|}
\hline & $\begin{array}{c}\text { Expectations from } \\
\text { training }\end{array}$ & $\begin{array}{c}\text { Motivation to } \\
\text { learn }\end{array}$ & $\begin{array}{c}\text { Reaction to } \\
\text { training }\end{array}$ & $\begin{array}{c}\text { Organizational } \\
\text { commitment }\end{array}$ \\
\hline Expectations from training & 1.00 & - & - & - \\
\hline Motivation to learn & 0.61 & 1.00 & - & - \\
\hline Reaction to training & 0.53 & 0.55 & 1.00 & - \\
\hline Organizational commitment & 0.36 & 0.48 & 0.61 & 1.00 \\
\hline
\end{tabular}

\section{Table 2: Presents the model summary of regression statistics of the independent variables}

\begin{tabular}{|c|c|c|c|c|}
\hline $\begin{array}{c}\text { Regression } \\
\text { Statistics }\end{array}$ & $\begin{array}{c}\text { Motivation to } \\
\text { learn }\end{array}$ & $\begin{array}{c}\text { Reaction to } \\
\text { training }\end{array}$ & $\begin{array}{c}\text { Expectations } \\
\text { from training }\end{array}$ & $\begin{array}{c}\text { Organizational } \\
\text { commitment }\end{array}$ \\
\hline Multiple R & 0.52 & 0.71 & 0.67 & 0.41 \\
\hline R Square & 0.27 & 0.51 & 0.45 & 0.17 \\
\hline Adjusted R Square & 0.26 & 0.50 & 0.44 & 0.16 \\
\hline Standard Error & 0.52 & 0.42 & 0.45 & 0.55 \\
\hline
\end{tabular}

Table 3: Describes output of coefficients from regression analysis

\begin{tabular}{|c|c|c|c|c|}
\hline & Coefficients & Standard Error & t Stat & P-value \\
\hline Intercept & 2.63 & 0.31 & 8.52 & $1.67 \mathrm{E}-11$ \\
\hline Motivation to learn & 0.34 & 0.08 & 4.43 & $4.77 \mathrm{E}-05$ \\
\hline Intercept & 1.96 & 0.28 & 7.07 & $3.46 \mathrm{E}-09$ \\
\hline Reaction to training & 0.51 & 0.07 & 7.37 & $1.16 \mathrm{E}-09$ \\
\hline Intercept & 1.18 & 0.43 & 2.76 & 0.007943 \\
\hline Expectations from training & 0.75 & 0.11 & 6.58 & $2.15 \mathrm{E}-08$ \\
\hline Intercept & 2.81 & 0.35 & 7.93 & $1.45 \mathrm{E}-10$ \\
\hline Organizational commitment & 0.29 & 0.09 & 3.31 & 0.001662 \\
\hline
\end{tabular}


However, "organizational commitment" showed weak positive linear relationship $(r=0.36)$. The details of the Pearson correlation matrix are presented in Table 1.

Table 2 explains the simple regression of the independent variables. A positive relation among all the independent variables was observed with the dependent variable. The regression coefficient of "reaction to training" was found to be high $(r=71)$, whereas regression coefficient of "organizational commitment" was $r=41$.

Table 3 explain statistical differences between the independent variables and the dependent variable, individually. The $p$ value for all the independent variables were lower than the 0.05 (C.I). Therefore, a relationship was observed between the independent variables and the dependent variable (acquired knowledge).

Figure 1 depicts the mean independent variable scores for male and female participants on the Likert scale. The female participants were perceived to be less motivated and less committed to their organizations. Furthermore, their expectation from training was also low compared to their male counterparts, and these attributes reflected their satisfaction level at the end of the training which was also found to be low among female participants.

\section{DISCUSSION}

This study mainly attempted to evaluatethe personality traits; expectation, satisfaction, motivation to learn, organizational commitment and their overallrole on the acquired knowledge during the training program. The role of the personality traits is essential to investigate because of the clinical competency of the dental professionals. ${ }^{13}$ Through the quantitative research described in previous section, we observed a positive correlation between the variables of this study. Moreover, through simple linear regression, the $p$ value for each personality trait tested the alternate hypothesis.All the independent variables were observed to be less than 0.05 alpha. Hence, the alternate hypothesis of this study is accepted.

Through widely used Pearson correlation matrix, linear dependence of the independent variables were observed. A positive correlation was found among all the variables used in this analytical study. Before any training program, expectations have found to be high always. This empirical study tested "expectations from learning" attribute ofthe dental professionals. The mean score on the Likert scale was (3.69) with the least standard deviation of all the independent variables i.e., 0.53 , showing a minimal variation towards expectations from training among the respondents. This can be explained by the fact that the learner readiness has a direct correlation on the acquired knowledge during the training. For example, if a trainee is going to learn how to operate accounting software, he or she needs to know how to use a computer. When trainees have the basic skills to perform training activities and basic knowledge about what kinds of activities they will perform during training, they are mentally prepared to participate in training activities and their learning level will rise. In a similar fashion, the trainees with higher expectations from training would more likely to excel in their training effectively. ${ }^{14}$

The second trainee characteristic, i.e., motivation plays a key role in acquired training and urge for learning. ${ }^{15}$ The value observed on Likert scale was $3.91 \pm 0.91$ for this personality trait. Motivation spurs a trainee towards learning and productivity with subsequent learning outcomes. ${ }^{16} \mathrm{It}$ is a trainee related factor that is considered to be the key competence required when any learning model is introduced to trainees. In this study, a positive correlation was observed between motivation to learn and expectations from training. Furthermore, the results also suggest that personality attributes such as "motivation to learn" and "expectations from training" among dental professionals are essential for acquisition of knowledge. . $^{1718}$ Reaction to training refers the extent to which training fulfilled trainee's expectations. The trainees showed mean value of $(3.89 \pm 0.11)$ on a Likert scale. However, the reliability of such results is generally ambiguous. The index based on retrospective query could be subjected to cognitive distortion. To overcome this ambiguity, a simple measure was contemplated, asking trainees about the perception of the training outcome. The perception of training was examined by asking (e.g., extent to which the content of the training program is useful for your respective job?), removes some of the subjectivity and recall bias.

The results of this study show a positive relationship between organizational commitment and knowledge acquired from training $(4.00 \pm 0.86)$. A committed employee would be committed with his work, productivity, and career. The higher output is directly correlated with organizational commitment. A committed employee would be more focused and interpret training as an indicative of commitment shown by the organization to him, and which he may reciprocate through his commitment to the organizational by excelling in knowledge acquisition during the training. A strong commitment to an organization, or work unit from the employees motivate them to use in their jobs what they have learned in their training.

Surprisingly, the female dental professionals were less motivated and less committed to their organization (Figure 1). It is generally seen that females are more moti- 
vated and have higher expectations from the training program. However, the findings of this study are contrariwise. The small sample size of female participants might be the reason of this unexpected observation. Mean scores of all the independent variables suggest that the male dental practitioners consider these trainee characteristics important and vital to acquiring knowledge compared to their female counterparts. The male practitioners considered "organizational commitment" an important trait to acquire knowledge, whereas, the female practitioners considered "reaction to training" vital to acquiring knowledge.

The limitations of this study include the quantitative technique used to collect date.To achieve the goals and objectives, the qualitative techniques are also recommended in future studies to acquire more accurate data and results. The open-ended questions give participants the opportunity to respond in their own words inqualitative technique, rather than forcing them to choose from fixed responses in quantitative technique. ${ }^{19}$ Secondly, the validity and reliability of the training effectiveness, which was derived from the single source i.e., course supervisor. Although the feedback from a supervisor helps in making the medical and dental education system more productive. ${ }^{20}$ However, the possibility of biasness might be increased due to variety of factors related to course supervisors such as sex/racial bias, personality characteristics, personal relationship with the trainee and favoritism. ${ }^{21}$ Future research may be focused on combination of both subjective and objective measures instead of just one evaluation method.Moreover, validity and reliability of training program may be enhanced by introducing two or more course supervisors to remove biasness. Thirdly, the generalizability of this study is in jeopardy due to the small sample size, which was limited to one dental institute and one curriculum only. Despite all these limitations, this investigationstill unveiled some interesting findings. In near future, studies examining the self-efficacy and attitudes of the trainees would be interesting to evaluate. Moreover, analysis of independent variable at subscales levels would also be interesting to examine.

\section{CONCLUSION}

In conclusion, it can be deduced that:

- A combination of personality traits is vital for dental professionals to excel in dental programs.

- Female dental professionals showed diminished importance topersonality traits on the Likert scale compared to male counterparts.

\section{ACKNOWLEDGEMENT}

The project was financially supported by Vice Deanship of Research Chairs, King Saud University, Riyadh; Kingdom of Saudi Arabia.

\section{CONFLICT OF INTEREST}

The author(s) declared no potential conflicts of interest with respect to the research, authorship, and/or publication of this article.

\section{REFERENCES}

1. Taichman RS, Parkinson JW, Nelson BA, Nordquist B, Ferguson-Young DC, Thompson JF. Leadership training for oral health professionals: a call to action. Journal of Dental Education. 2012;76(2):185-91. PMid:22319083.

2. Noe RA. Employee training and development: McGraw-Hill//rwin Boston, MA; 2002.

3. Goldstein IL. Training in organizations: Needs assessment, development, and evaluation: Thomson Brooks/Cole Publishing Co; 1993.

4. Velada R, Caetano A, Michel JW, Lyons BD, Kavanagh MJ. The effects of training design, individual characteristics and work environment on transfer of training. International Journal of Training and Development. 2007;11(4):282-94. http://dx.doi.org/10.1111/j.1468-2419.2007.00286.x

5. Clarke N. Job/work environment factors influencing training transfer within a human service agency: Some indicative support for Baldwin and Ford's transfer climate construct. International Journal of Training and Development. 2002;6(3):146-62. http://dx.doi.org/10.1111/1468-2419.00156

6. Ruona WE, Leimbach M, Holton EF, Bates R. The relationship between learner utility reactions and predicted learning transfer among trainees. International Journal of Training and Development. 2002;6(4):218-28. http:// dx.doi.org/10.1111/1468-2419.00160.

7. Switzer KC, Nagy MS, Mullins ME. The influence of training reputation, managerial support, and self-efficacy on pre-training motivation and perceived training transfer. Applied HRM Research. 2005;10(1):21-34.

8. Bates R. A critical analysis of evaluation practice: the Kirkpatrick model and the principle of beneficence. Evaluation and Program Planning. 2004;27(3):341-7. http://dx.doi.org/10.1016/j.evalprogplan.2004.04.011.

9. Scaduto A, Lindsay D, Chiaburu DS. Leader influences on training effectiveness: motivation and outcome expectation processes. International Journal of Training and Development. 2008;12(3):158-70. http://dx.doi. org/10.1111/j.1468-2419.2008.00303.x.

10. Aguinis $H$, Kraiger $K$. Benefits of training and development for individuals and teams, organizations, and society. Annual Review of Psychology. 2009;60:451-74. http://dx.doi.org/10.1146/annurev.psych.60.110707.163505; PMid:18976113.

11. Cannon-Bowers JA, Salas E, Tannenbaum SI, Mathieu JE. Toward theoretically based principles of training effectiveness: A model and initial empirical investigation. Military Psychology. 1995;7(3):141. http://dx.doi. org/10.1207/s15327876mp0703_1.

12. Tannenbaum SI, Mathieu JE, Salas E, Cannon-Bowers JA. Meeting trainees' expectations: The influence of training fulfillment on the development of commitment, self-efficacy, and motivation. Journal of Applied Psychology. 1991;76(6):759. http://dx.doi.org/10.1037/0021-9010.76.6.759.

13. Vohra F, Shah AH, Zafar MS, Kola Z. Knowledge and practice of implantretained restorations among dental students in Saudi Arabia. Pakistan Journal of Medical Sciences. 2015;31(4):848. PMid:26430416 PMCid:PMC4590372.

14. Salas E, Tannenbaum SI, Kraiger K, Smith-Jentsch KA. The science of training and development in organizations: What matters in practice. Psychological Science in the Public Interest. 2012;13(2):74-101.http://dx.doi. org/10.1177/1529100612436661;PMid:26173283.

15. Yarrow K, Brown P, Krakauer JW. Inside the brain of an elite athlete: the neural processes that support high achievement in sports. Nature 
Reviews Neuroscience. 2009;10(8):585-96. http://dx.doi.org/10.1038/nrn2672; PMid:19571792

16. Alrahabi M, Zafar MS, Ahmed N. Effects of handpiece speed on the performance of undergraduate dental students in preclinical training. Journal of Taibah University Medical Sciences. 2015;10(1):50-5. http://dx.doi. org/10.1016/j.jtumed.2014.12.005.

17. Yeo GB, Neal A. A multilevel analysis of effort, practice, and performance: effects; of ability, conscientiousness, and goal orientation. Journal of Applied Psychology. 2004;89(2):231. http://dx.doi.org/10.1037/0021-9010.89.2.231 PMid:15065972.

18. Gallagher J, Clarke W, Wilson N. Understanding the motivation: a qualitative study of dental students' choice of professional career. European Journal of Dental Education. 2008;12(2):89-98. http://dx.doi.org/10.1111/j.16000579.2008.00506.x PMid:18412737.

19. Al-Busaidi ZQ. Qualitative research and its uses in health care. Sultan Qaboos University Medical Journal. 2008;8(1):11-9. PMid:21654952 PMCid:PMC3087733.

20. Hafeez K, Wahaj A, Zafar MS. Evolving medical and dental education system in pakistan. Pak Armed Forces Medical Journal. 2015; 65(4): 564-67.

21. Ranney RR, Wilson MB, Bennett RB. Evaluation of applicants to predoctoral dental education programs: review of the literature. Journal of Dental Education. 2005;69(10):1095-106. PMid:16204675.

\section{SUMMARY}

- A questionnaire was prepared and distributed to 96 dental practitioners undertaking the week-long continuing medical education (CME) on "dental pharmacology and patient safety" to explore the role of trainee characteristics on acquired knowledge.

- A positive correlation was observed between the trainee characteristics (motivation to learn, reaction to training, expectations from training, organizational commitment) and acquired knowledge.

- A combination of personality traits is essential for dental professionals to excel in dental programs. 